\title{
Movement of Dislocations in the Sub-Surface of a Polycrystalline Metal by Cavitation Peening Observed by Transmission Electron Microscopy
}

\author{
Osamu Takakuwa ${ }^{1}$, Akihiko Chiba ${ }^{2}$, Hitoshi Soyama ${ }^{1}$ \\ ${ }^{1}$ Department of Nanomechanics, Graduate School of Engineering, Tohoku University, Sendai, Japan \\ ${ }^{2}$ Institute for Materials Research, Tohoku University, Sendai, Japan \\ Email: o takakuwa@mm.mech.tohoku.ac.jp
}

Received 8 January 2015; accepted 27 January 2015; published 30 January 2015

Copyright (C) 2015 by authors and Scientific Research Publishing Inc.

This work is licensed under the Creative Commons Attribution International License (CC BY). http://creativecommons.org/licenses/by/4.0/

\section{(c) (i) Open Access}

\begin{abstract}
The impact produced when cavitation bubbles collapse can be utilized to modify surfaces in the same way as shot peening and it is called cavitation peening (CP). CP is one of a number of surface modification techniques used to improve the fatigue strength of metallic materials by introducing compressive residual stress. Although it has been shown by an X-ray diffraction method that $\mathrm{CP}$ decreases the micro-strain related to dislocations in the sub-surface of a polycrystalline material, the mechanism for this decrease is unclear. In this paper, the movement of dislocations by $\mathrm{CP}$ was observed using transmission electron microscopy (TEM).
\end{abstract}

Keywords

Microstructure, Transmission Electron Microscopy, Dislocation, Surface Modification, Cavitation

\section{Introduction}

Cavitation normally causes severe damage in hydraulic machinery such as pumps and turbines by the impact produced by cavitation bubbles collapsing. On the other hand, local plastic deformation caused by impact enhances the fatigue strength of materials, and this is widely known as shot peening. Cavitation impact utilized for surface modification is called "cavitation peening (CP)", as shot is not required [1]-[5]. It was found that mechanical finishing and/or heat treatment give(s) rise to micro-strain in the sub-surface of a polycrystalline metal due to the compressive residual stress introduced and that this micro-strain can be reduced by CP [6]. In this pa-

How to cite this paper: Takakuwa, O., Chiba, A. and Soyama, H. (2015) Movement of Dislocations in the Sub-Surface of a Polycrystalline Metal by Cavitation Peening Observed by Transmission Electron Microscopy. Materials Sciences and Applications, 6, 140-144. http://dx.doi.org/10.4236/msa.2015.62017 
per, the strain between adjacent grains and random strain in grains is referred to as micro-strain. This phenomenon is due to dislocations and lattice defects. The mechanism by which micro-strain is reduced by CP is unclear; therefore, in this work, the sub-surface of a polycrystalline metal peened by CP was directly observed using transmission electron microscopy (TEM).

$\mathrm{CP}$ enhances the fatigue strength of metallic materials by introducing compressive residual stress in the sub-surface in the same way as shot peening [1]-[5]. Although the compressive residual stress introduced by CP is small and shallow, the improvement in fatigue strength is better than that achieved by shot peening [2]. It was found that the full width at half maximum (FWHM) of the X-ray diffraction profile decreased after CP and it was shown by a fundamental parameter approach that $\mathrm{CP}$ caused a reduction in the micro-strain introduced by mechanical finishing and/or heat treatment [6]. Since micro-strain is a potential precursor for fracture, a reduction in this should enhance the fatigue strength. However, as mentioned above, the mechanism by which the micro-strain is reduced by CP needs clarification. Several studies have been done on recovery through polygonization and recrystallization. Also, in those studies, TEM was used for observing dislocations [7]-[9]. It was recognized that, in general, the recovery was due to annealing [10]. However, relaxation of micro-strain by CP does not require annealing. Since ultrasonic vibration can cause dislocations to move in metal [11], the high-frequency vibration induced by cavitation bubbles collapsing might also do this. Thus, microstructural analysis of materials peened by $\mathrm{CP}$ is needed.

In this paper, in order to clarify the mechanism by which micro-strain is decreased by CP, the sub-surface microstructure of peened samples was observed using TEM and scanning electron microscopy (SEM). It is noted that this is the first time that movement of dislocations in the sub-surface of polycrystalline metal by CP has been reported.

\section{Experimental Apparatus and Procedures}

The material chosen for the analysis was tool steel alloy (Japanese Industrial Standard JIS SKD61) which is used for forging die, and on which CP has been used to extend the life time [12]. The test material was heattreated in the same way as hot forging die, that is, by heat treating at $873 \mathrm{~K}$ for $1 \mathrm{~h}$, then quenching, followed by further heat treatments at $1123 \mathrm{~K}$ for $1 \mathrm{~h}$ and $1295 \mathrm{~K}$ for $1.5 \mathrm{~h}$. The material was then tempered at $833 \mathrm{~K}$ for $5 \mathrm{~h}$. The surface of the specimen was polished using \#1500 grade and \#2000 grade emery paper and finished by polishing using diamond paste. The size of the specimen was $20 \mathrm{~mm}$ long, $15 \mathrm{~mm}$ wide, and $18 \mathrm{~mm}$ thick. CP was carried out using a cavitating jet in air [4] at an injection pressure of $30 \mathrm{MPa}$ with a nozzle diameter of $1 \mathrm{~mm}$. The other condition was same as reported in previous report [6]. The processing time per unit length was 10 $\mathrm{s} / \mathrm{mm}$. A non-peened specimen (finished by polishing) used as a control is referred to as the NP specimen in this experiment.

To make TEM observations it is important to know the depth of the work-affected layer. In order to find this the residual stress and FWHM as a function of depth were evaluated by X-ray diffraction using a $\sin ^{2} \psi$ method. The analysis was done using $\mathrm{Cr} \mathrm{K} \alpha \mathrm{X}$-rays from a tube operated at $30 \mathrm{kV}$ and $8 \mathrm{~mA}$. The X-rays were counted for $3 \mathrm{sec}$ at each step using a scintillation counter at angles of $\psi=0$, 22.8, 33.2, 42.2 and $50.8 \mathrm{deg}$. Here, $\psi$ is the angle between the normal to the surface and the normal to the diffractive face. The lattice plane hkl was (211). The diffractive angle $2 \theta_{0}$ without strain was $156.4 \mathrm{deg}$ and the stress factor in the X-ray diffraction method was $-318.0 \mathrm{MPa} / \mathrm{deg}$.

The surface of the specimen was etched using $5 \%$ nital so that the grain structure could be analyzed by SEM at $5 \mathrm{kV}$. In order to investigate dislocations, the specimens were observed using TEM. Specimens for TEM were cut by a wire cutting technique, polished from beneath using emery paper, and finally thinned by electrolytic polishing using a dual jet electropolisher. The settings for the electropolisher were $20 \mathrm{~V}$ and $263 \mathrm{~K}$, and the electrolyte was $5 \%$ nital. The specimen size before electropolishing was $3 \mathrm{~mm}$ in diameter and $80 \mu \mathrm{m}$ thick. The final thickness in the observation area near the center was less than $20 \mu \mathrm{m}$. TEM observations were done at 200 $\mathrm{kV}$.

\section{Results}

Figure 1 shows the residual stress and FWHM at $\psi=0$ of the NP and CP specimens as a function of depth. The FWHM of both NP and CP specimens has been normalized by the FWHM of the NP specimen at $z=0 \mu \mathrm{m}$. The residual stress of the NP specimen was about -200 MPa and that of the CP specimen was about $-900 \mathrm{MPa}$ at the 


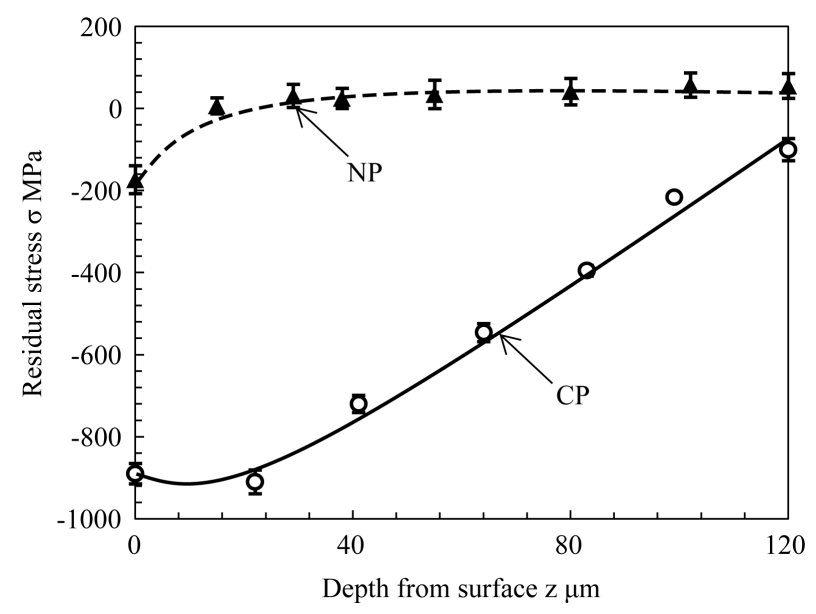

(a)

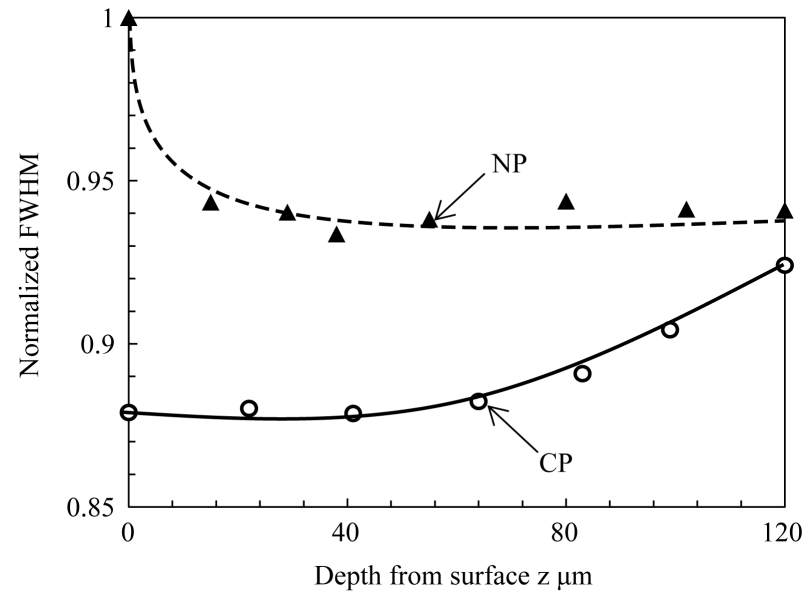

(b)

Figure 1. Residual stress and variation of the FWHM with depth from the surface. (a) Residual stress with depth from the surface; (b) Normalized FWHM with depth from the surface.

surface. In the case of the CP specimen, the depth of the compressive residual stress introduced by $\mathrm{CP}$ is more than $120 \mu \mathrm{m}$ and is deeper than that of the NP specimen. The FWHM of the CP specimen is smaller than that of the NP specimen at $z<120 \mu \mathrm{m}$. Judging from both the residual stress and the FWHM, it can be concluded that the depth of the CP work-affected layer is greater than $120 \mu \mathrm{m}$. Therefore, the region observed by TEM was within the work-affected layer, as the thickness of the specimen at this point was less than $20 \mu \mathrm{m}$.

Figure 2 shows micrographs of the surfaces of the NP and CP specimens observed by SEM at a magnification of 3000. The martensite structure, which has the appearance of creases in the grains, was observed in both NP and CP specimens. The size and shape of the grains peened by CP were similar to those in the NP specimen. Although the grains might collapse by increasing the intensity of the CP [2], the grains in the material were not very much deformed with the conditions used here.

In order to observe the effect of CP on dislocations, TEM observations at a magnification of 10,000 were done. Figure 3 shows micrographs of the results. Lath martensite was observed in these specimens. The dislocations in the NP specimen are random, as the grains appear to be gray. In the case of the micrograph of the CP specimen, the contrast in the lath martensite was greater than that of the NP specimen, as the dislocations had moved and accumulated. To evaluate the crystallinity, electron diffraction patterns of the regions shown in Figure 3 were obtained.

Figure 4 shows the electron diffraction patterns of the NP and CP specimens. The crystallinity, which is related to dislocations, can be evaluated from the electron diffraction pattern. If the dislocations are randomly 


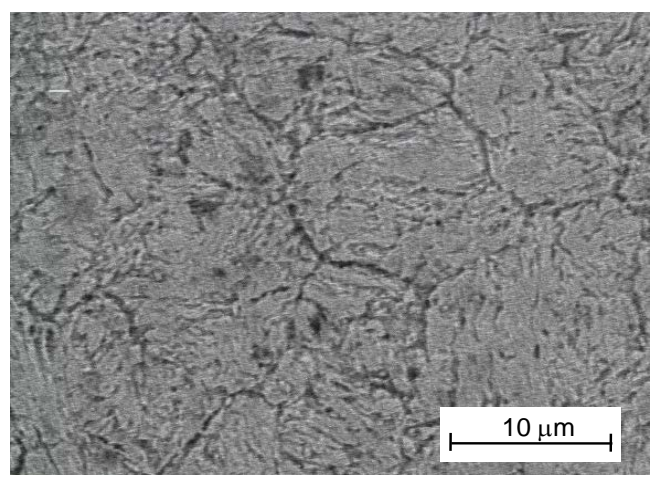

(a)

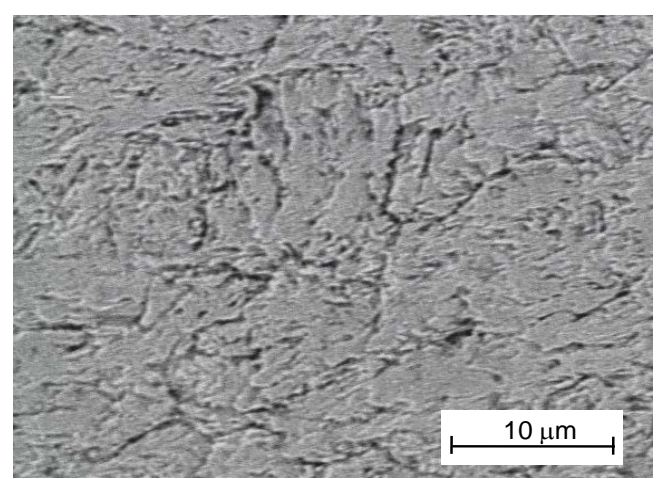

(b)

Figure 2. Micrograph observed by SEM at a magnification of 3000. (a) Not-peened (NP); (b) Cavitation-peened (CP).

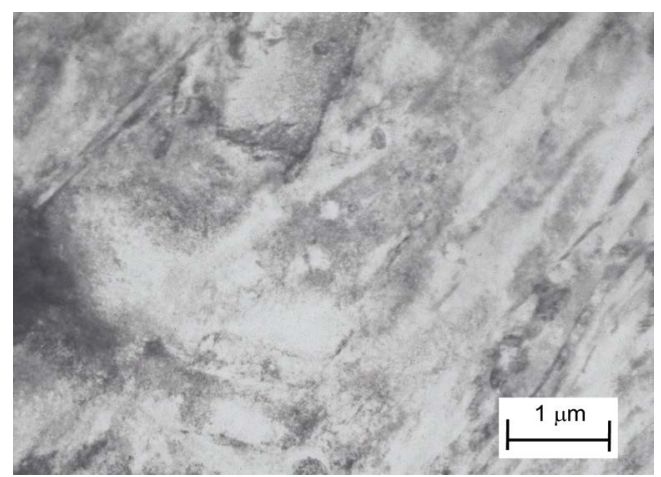

(a)

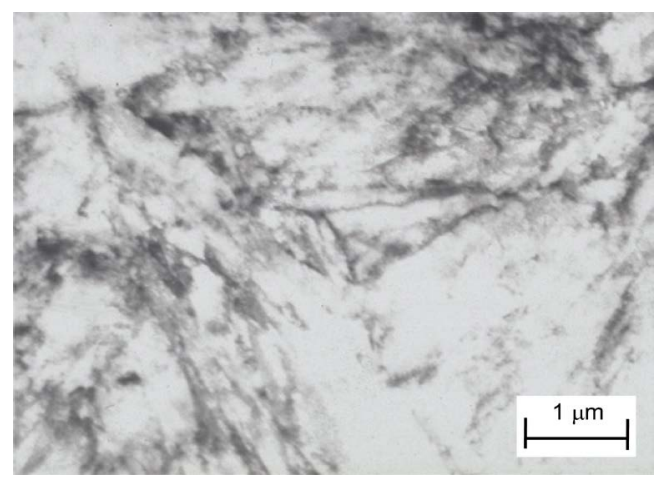

(b)

Figure 3. Micrograph observed by TEM at a magnification of 10,000. (a) Non-peened (NP); (b) Cavitation-peened (CP).

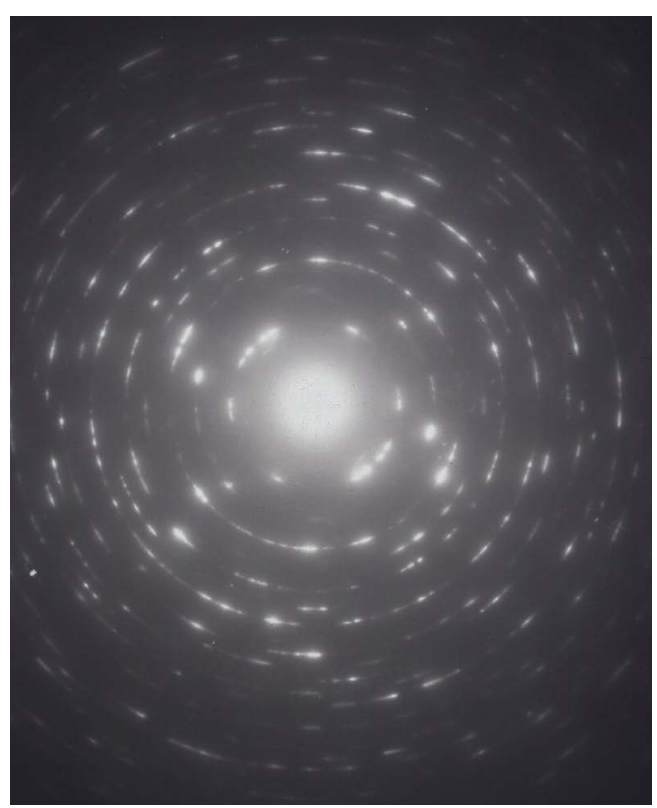

(a)

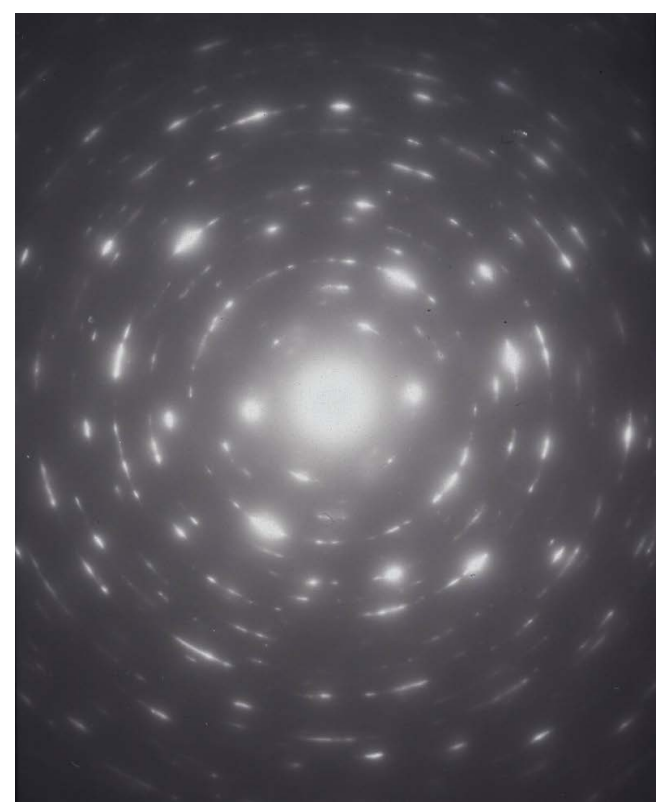

(b)

Figure 4. Electron diffraction pattern observed by TEM (obtained from the region shown in Figure 3). (a) Non-peened (NP); (b) Cavitation-peened (CP). 
placed, the electron diffraction pattern shows a ring-like pattern. Although the diffraction pattern from the NP specimen has a ring-like pattern, in contrast, the diffraction pattern from the CP specimen has a discrete spot pattern. This is more remarkable in the inner circle. This shows that CP causes the dislocations to move. The reason for this is that the high-frequency vibration induced by cavitation bubbles collapsing moves dislocations in the same way as ultrasonic vibration [11]. Although the area observed by TEM was restricted, the result is applicable to the whole area, since the relationship between the FWHM and the micro-strain applies to the X-ray diffraction measurement area of $4 \mathrm{~mm} \times 4 \mathrm{~mm}$.

\section{Conclusion}

In order to clarify the mechanism by which CP decreases micro-strain, the surface of tool steel alloy was treated by CP and observed by TEM. It was found that the micro-strain, which had been induced by heat treatment and/or mechanical finishing, can be reduced due to movement of dislocations induced by CP.

\section{Acknowledgements}

This work was partly supported by JSPS KAKENHI Grant number 24360040.

\section{References}

[1] Soyama, H., Saito, K. and Saka, M. (2002) Improvement of Fatigue Strength of Aluminum Alloy by Cavitation Shotless Peening. Journal of Engineering Materials and Technology, 124, 135-139. http://dx.doi.org/10.1115/1.1447926

[2] Macodiyo, D.O. and Soyama, H. (2003) Cavitation Shotless Peening for Improvement of Fatigue Strength of Carbonized Steel. International Journal of Fatigue, 25, 1217-1222. http://dx.doi.org/10.1016/S0142-1123(03)00121-X

[3] Soyama, H. and Macodiyo, D.O. (2005) Fatigue Strength Improvement of Gears Using Cavitation Shotless Peening. Tribology Letters, 18, 181-184. http://dx.doi.org/10.1007/s11249-004-1774-7

[4] Soyama, H., Kikuchi, T., Nishikawa, M. and Takakuwa, O. (2010) Introduction of Compressive Residual Stress into Stainless Steel by Employing a Cavitating Jet in Air. Surface and Coatings Technology, 205, 3167-3174. http://dx.doi.org/10.1016/j.surfcoat.2010.11.031

[5] Soyama, H. (2014) The Use of Cavitation Peening to Increase the Fatigue Strength of Duralumin Plates Containing Fastener Holes. Materials Sciences and Applications, 5, 430-440. http://dx.doi.org/10.4236/msa.2014.56047

[6] Soyama, H. and Yamada, N. (2008) Relieving Micro-Strain by Introducing Macro-Strain in a Polycrystalline Metal Surface by Cavitation Shotless Peening. Materials Letters, 62, 3564-3566. http://dx.doi.org/10.1016/j.matlet.2008.03.055

[7] Ryan, N.D. and Mcqueen, H.J. (1986) Dynamic Recovery and Strain Hardening in the Hot Deformation of Type 317 Stainless Steel. Materials Science and Engineering, 81, 259-272. http://dx.doi.org/10.1016/0025-5416(86)90267-3

[8] Kim, S.I. and Yoo, Y.C. (2001) Dynamic Recrystallization Behavior of AISI 304 Stainless Steel. Materials Science and Engineering A, 311, 108-113. http://dx.doi.org/10.1016/S0921-5093(01)00917-0

[9] Belyakov, A., Kimura, Y. and Tsuzaki, K. (2005) Recovery and Recrystallization in Ferritic Stainless Steel after Large Strain Deformation. Materials Science and Engineering A, 403, 249-259. http://dx.doi.org/10.1016/j.msea.2005.05.057

[10] Beck, P.A. (1954) Annealing of Cold Works Metals. Advances in Physics, 3, 245-324. http://dx.doi.org/10.1080/00018735400101203

[11] Ostrovskii, I., Ostrovskaya, N., Korotchenkov, O. and Reidy, J. (2005) Radiation Defects Manipulation by Ultrasound in Ionic Crystals. IEEE Transactions on Nuclear Science, 52, 3068-3073. http://dx.doi.org/10.1109/TNS.2005.861476

[12] Soyama, H., Takano, Y. and Ishimoto, M. (2000) Peening of Forging Die by Cavitation. Technical Review of Forging Technology, 25, 53-57. 
Scientific Research Publishing (SCIRP) is one of the largest Open Access journal publishers. It is currently publishing more than 200 open access, online, peer-reviewed journals covering a wide range of academic disciplines. SCIRP serves the worldwide academic communities and contributes to the progress and application of science with its publication.

Other selected journals from SCIRP are listed as below. Submit your manuscript to us via either submit@scirp.org or Online Submission Portal.
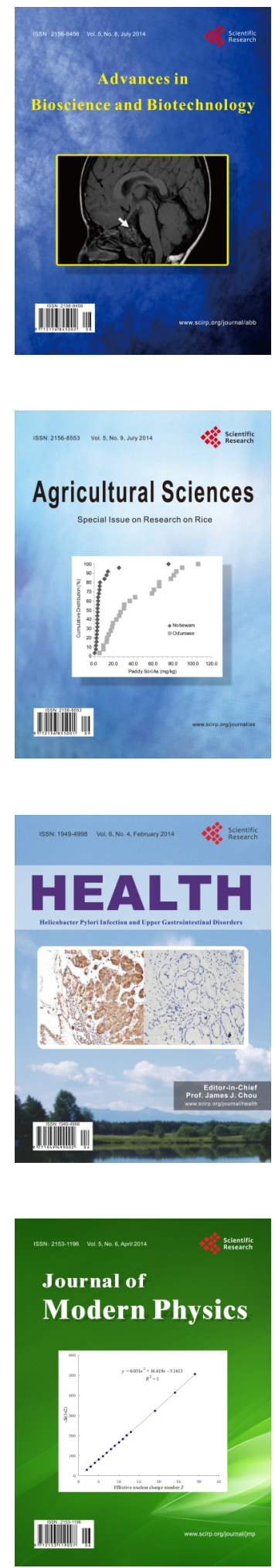
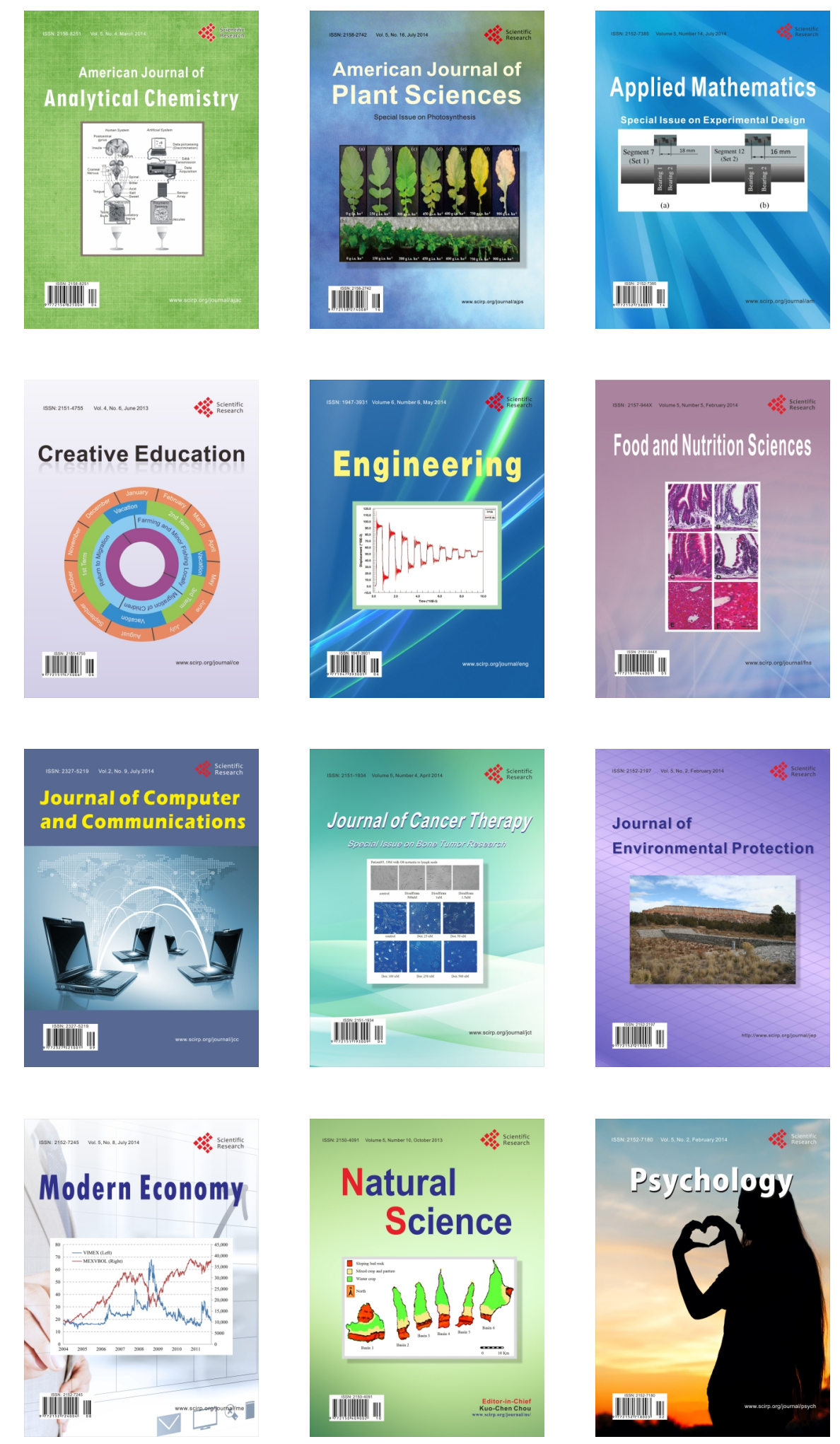